\title{
A experiência escolar de uma criança nordestina em
}

São Paulo

\author{
The scholar experience of a northwestern child in Sao \\ Paulo
}

Jacqueline SIMÕES

\section{RESUMO}

O presente depoimento tem por objetivo analisar o processo de aquisição da linguagem escrita por uma criança nordestina em São Paulo. Procuraremos demonstrar como a educação escolar pode contribuir para tornar a alfabetização desta criança significativa levando em consideração a singularidade de sua leitura do mundo manifestada através de sua linguagem corporal e cultural.

Palavras-chave: alfabetização, letramento, linguagem corporal.

\begin{abstract}
This testimony aims to analyze the process of acquisition of written language by a northwestern child in Sao Paulo. We intend to show how the scholar education is able to turn this child's literacy into a significant act taking into consideration the uniqueness of its reading of the world expressed through his cultural and body languages.
\end{abstract}

Index terms: alphabetization, literacy, body language. 
No período de abril a junho de 2007, realizei um estágio de observação na EMEF Mal. Eurico Gaspar Dutra, localizada no bairro da Vila Brasilina em São Paulo. As atividades do estágio foram de caráter obrigatório como parte dos programas de diferentes disciplinas, dentre elas, Fundamentos da Alfabetização/ Letramento da Educação de Jovens e Adultos.

Esse trabalho permitiu-me acompanhar o processo de aquisição da escrita de um grupo de trinta e quatro alunos com idade entre seis e oito anos, níveis variados de alfabetização assim como de socialização no universo escolar. A professora dessa classe é a senhora Márcia Cecconi, a quem manifesto agradecimentos pela oportunidade dessa análise e outras colaborações acadêmicas.

Com base nas observações dessa experiência gostaria de relatar o caso específico de um dos integrantes desse grupo. O nome do menino é Jeferson, tem sete anos, é migrante do Estado do Alagoas, mora com seus avós - em situação de pouco ou nenhum domínio da língua portuguesa escrita- em uma favela próxima à escola. Ele não manifesta interesse pelos conteúdos acadêmicos e tampouco pela integração com os colegas de classe em atividades como cantar "parabéns” para o aniversariante do dia ou por trabalhos em dupla.

A criança apresenta uma postura típica da vivência em espaços reduzidos: os braços estão sempre juntos ao corpo, os movimentos são curtos, é extremamente silencioso. Além disso, há dificuldade de memorização, de coordenação motora (a mão treme muito quando escreve) e para fazer interferências coerentes nos contextos criados para a manifestação dos alunos.

De acordo com a elaboração feita por Emília Ferreiro (2001) sobre os estágios de aquisição da escrita, a criança está no nível pré-silábico em transição para o silábico de valor sonoro. Essa oscilação fica evidente em produções escritas em que é chamado a escrever sozinho com o suporte de 
figuras e escrever sozinho, mas em situação de ditado coletivo. Como nos mostra a tabela ${ }^{1}$ a seguir.

\begin{tabular}{|l|l|}
\hline Com suporte de figuras & Ditado coletivo \\
\hline MHNHON & ABBI \\
\hline MBAI & OI \\
\hline MOHEH & CAD \\
\hline CAMEN & CA \\
\hline MOCIEE & OEF \\
\hline VEIR(?)UI & IU \\
\hline A(?)MẼ̃ & CIF \\
\hline AEAU EOEI & HIA \\
\hline
\end{tabular}

Diante do que foi exposto até aqui, parece-nos pertinente entender o desafio de alfabetizar essa criança por recursos pedagógicos que atentem para uma "educação de corpo inteiro". Conforme Colello (1995), o desenvolvimento da criança na sua plenitude, isto é, levando em consideração os aspectos motor e físico que tanto têm sido desconsiderados no âmbito das salas de aula. É possível pensar em atividades que envolvessem na escrita não só o uso da mão, mas do corpo todo como atividades de relaxamento (respirar fundo, alongar o corpo) e tensão (sentarse ereto, brincar com letras móveis - encontrá-las embaixo da carteira, por exemplo).

Da mesma forma parece necessário oferecer um “espaço de criação” (WINNICOTT, 1951) para que a criança possa construir sua posição subjetiva na escola, em São Paulo, na sua nova família. De modo que, esse espaço pudesse se converter em objeto de reflexão para que a criança

\footnotetext{
${ }^{1}$ Nessa atividade as palavras, tanto como suporte de figuras como em ditado coletivo, eram na seguinte ordem: abacaxi, baleia (também interpretada por golfinho ou tubarão), papagaio (também interpretada por arara), cachorro, coelho, formiga, casa e galinha (também interpretada por galo).
} 
estabelecesse vínculos com a linguagem oral e escrita e com a funcionalidade dessa última para a realidade que ela constrói e para o conhecimento que partilha com os outros agentes sociais.

Diante dos conceitos escolhidos para analisar o processo de aquisição da escrita dessa criança, considerei pertinente aplicá-los de modo a auxiliar a professora Márcia a alfabetizar o Jeferson. Portanto, prossegui a análise no segundo semestre deste mesmo ano, mas desta vez com o objetivo de alfabetizar a criança.

As atividades de alfabetização procuraram desenvolver o máximo de habilidades para a formação integral da criança. Desse modo, a escrita do próprio nome e dos nomes de colegas e familiares foram conduzidas pela professora de modo que ele pudesse refletir sobre a equivalência fonética e gráfica que existe em nossa língua. De forma semelhante foram conduzidas escritas de nomes de animais e de alimentos ou brincadeiras que ele aprecia. Essas tarefas permitiram que ele se apropriasse da escrita com aspectos da vida que tinham importância para ele. Segundo esse mesmo princípio, de aprender com significado, cuidei também para que a escrita não se limitasse às tarefas na sala de aula e assim, fizemos passeios pela escola para identificar o uso da escrita de letras e de números. Lemos as identificações das salas, o jornal da escola, os números do telefone público na secretaria.

Para desenvolver a capacidade de atenção e interferência coerente nos contextos tratados foi usado o reconto de histórias como "Primeira aventura de Alexandre” de Graciliano Ramos (1979). Com o suporte da biografia do autor (alagoano como o Jéferson) e uso de mapas com a localização geográfica da história, a criança era levada fazer inferências sobre a realidade do texto e da sua própria vida, por exemplo.

Os mapas foram usados muitas vezes para estabelecer pontes entre o nordeste e o sudeste levando em conta que a criança percorreu essa distância para estar em São Paulo. Também foram usados para localizar a provável 
origem das cantigas tradicionais que líamos na sala e brincávamos no recreio.

As atividades de escrita e leitura geram uma grande tensão física e mental na pessoa que se alfabetiza por isso durante as lições eram feitos exercícios de relaxamento do corpo, colocações divertidas para desanuviar a mente etc. Ainda pensando no desenvolvimento de habilidades motoras, trabalhamos exercícios físicos como andar a passos largos, movimentar-se mais pela sala sem intimidar-se.

Houve atividades práticas para o estímulo da autonomia como pesquisar o próprio caderno, os cartazes da sala e os colegas para buscar informações. Resolver, sem a mediação do adulto, os conflitos que surgiam no recreio ou na sala de aula. Esse foi um aspecto bastante cuidado no trabalho: estimular o máximo possível o convívio entre as crianças. Neste ponto, concordamos com Winnicott quando diz que "a brincadeira fornece uma organização para a iniciação de relações emocionais e assim propicia o desenvolvimento de contatos sociais” (WINNICOTT, 1971, p. 163).

Além disso, o estimulei para que falasse da própria vida para mim acreditando ser necessário para a criança contar com o apoio de um adulto para ajudá-lo a resolver seus conflitos internos e externos.

O resultado do trabalho é que agora, no final do mês de outubro, ele manifesta interesse pelos assuntos tratados na classe, está mais integrado aos colegas inclusive procurando-os espontaneamente para fazer lições ou brincadeiras. É capaz de fazer interferências coerentes conforme o que está sendo tratado. Além disso, sua linguagem corporal desenvolveu-se: não anda mais com os braços juntos ao corpo, movimenta-se pela sala de maneira menos tensa, segura o lápis com mais firmeza, não esconde a escrita com a mão livre, tem iniciativa de leitura. Abraça e conversa muito com os colegas que escolheu como mais próximos, tal situação significa um avanço em sua disposição afetiva. 
Apesar do Jéferson ainda estar “atrasado” em relação aos colegas no que se refere aos conteúdos escolares, ele já consegue escrever alfabeticamente como demonstra a tabela a seguir com as mesmas palavras das atividades demonstradas no início do depoimento. A atividade foi feita no final do mês de outubro em situação de ditado individual e sem suporte de figuras.

\begin{tabular}{|l|}
\hline ABCACI \\
\hline BALERA \\
\hline PAGARO \\
\hline CAXORO \\
\hline COEIO \\
\hline FOMIGA \\
\hline CASA \\
\hline GALIRA \\
\hline
\end{tabular}

Concluí que o trabalho feito com o Jéferson na escola contribuiu para a integração de sua personalidade, pois, como disse Winnicott, compreendemos que "[algumas crianças] só aprendem segundo o seu próprio ritmo e à sua própria maneira, quase em segredo” (WINNICOTT, 1971, p. 233). Portanto, acredito que a escola converteu-se em um local onde o Jeferson compreendeu que, na sociedade letrada em que vivemos, adquirir o sistema de escrita o torna por um lado, co-autor da história humana e por outro, autor de sua própria história. É o que nos diz Biarnès (1998) quando afirma que a letra é objeto para o outro, quando eu a escrevo; objeto do outro, se a leio; e ainda, um espelho mágico no qual eu me (re)conheço e me descubro outro. 


\section{Referências bibliográficas}

BIARNÈS, Jean (1998). O ser e as Letras: da voz à letra, um caminho que construímos todos. Rev. Fac. Educ. vol.24 n.2 São Paulo July/Dec.

Disponível em:

http://www.scielo.br/scielo.php?script=sci_arttext\&pid=S010225551998000 200009

COLELLO, Silvia M. Gasparian (1995). Alfabetização em questão. Rio de Janeiro: Paz e Terra.

FERREIRO, Emília (2001). Reflexões sobre alfabetização. 24 ed. São Paulo: Cortez.

SILVA, Nilce da; PESCATORE, Birgit G. Von; BACCARIN, Raquel Yvone Arantes (2006). Um original ambiente de leitura. São Paulo. Disponível em: http://www.usp.br/jorusp/arquivo/2006/jusp754/pag12.htm

WINNICOTT, D.W (1971). A criança e o seu mundo. 2 ed, Rio de Janeiro: Zahar Editores.

\section{Autora}

\section{Jacqueline Simões}

Graduanda em Pedagogia pela FEUSP. Filiação institucional: Faculdade de Educação da Universidade de São Paulo (FE-USP).

jacqueline.simoes@usp.br

\section{Como citar este depoimento:}

SIMÕES, Jacqueline. A experiência escolar de uma criança nordestina em São Paulo. Revista ACOALFAplp: Acolhendo a Alfabetização nos Países de Língua portuguesa, São Paulo, ano 2, n. 4, 2008. Disponível em: $<$ http://www.mocambras.org > e ou <http://www.acoalfaplp.org >. Publicado em: março 2008. 